\title{
CAR INDUSTRY ENTERPRISES \\ IN POLAND: STRATEGIC PRIORITIES \\ IN THE CIRCUMSTANCES OF \\ DEPRESSION ON THE MARKET
}

\author{
Michat BARAN
}

\begin{abstract}
A B S T R A C T
It is in the recent years that the automotive branch has been remarkably affected by the global economic crisis. The companies located in Poland make up a significant element of the global system. The paper analyses the most important data that describe the activities of these companies in the years of the crisis (the research covered the period from 2005 through 2012). It is possible to formulate the thesis that this is the group of entities that coped relatively well with the difficult situation encountered in the environment. Thanks to the conducted analysis it was possible to point to the regularities that increased the possibility success in this kind of circumstances.
\end{abstract}

KEY WORDS

firm goal (L210), organizational behaviour (L220), firm size (L250)

DOI: 10.1515/emj-2016-0016
Corresponding author:

Michał Baran

Jagiellonian University, Institute of Economics, Finance and Management

e-mail: michal.baran@uj.edu.pl

\section{INTRODUCTION}

The generally advantageous situation of the Polish enterprises that represent the car industry branch, observed upon the ending of the recent economic depression is a valuable example of how to effectively administer the possessed resources in similar circumstances. This subject has not hitherto been thoroughly explored although it potentially allows to gain knowledge that is of substantial practical significance with regard to the possibility of appearance of similar depressions. The major thesis of the present discussion which pronounces that the Polish car industry enterprises got through with the depression better than the entire car industry sector when viewed from the European perspective, was verified on the basis of the analysis of major data such as investments, possessed assets, profits, employment and achieved turnovers (the research covered the period from 2005 through 2012). In its theoretical part, the discussion focused not only on the analysis of the effects of the depression itself for the European car industry branch but also on the description of the most significant phenomena that were determinative of the possibility of successful development of this kind of activity. In the final fragments of the text the characteristic elements of the way along which the investigated entities had followed in order to reach the final competitively advantageous position were indicated.

\section{LITERATURE REVIEW}

The world economic crisis which came to the open in the second half of the first decade of the 21 st century considerably affected the automotive branch (Brinkmann, 2011). In case of Poland this branch is unequivocally oriented toward the cooperation with the global system, particularly through its role 
of a supplier of a wide assortment of sub-assemblies and, less frequently, of finished vehicles (Globalization..., 2003). The largest domestic enterprises of this sector make up a part of the great international corporations and are designed to satisfy their needs (Automobile..., 2006). On the basis of EUROSTAT data one may estimate that in midEastern Europe the Polish companies generated 36\% of turnovers of automotive branch. In the structure of Polish export, the automotive branch occupies one of the key places and is responsible for $15 \%$ of the value of the entire Polish export. In countries like Poland this branch was exposed to strong pressure resulting from the cyclical fluctuations in the economic situation during the last crisis (Keeley, 2010). For that reason one may expect that the difficult situation observed at the European Union market will unfavorably affect the leading companies in Poland and the tendency of these companies towards making investments (Peters, 2011). In order to understand the scale of the crisis between 2005 and 2012 it is possible to use the data from the European Automobile Manufacturers Association website (www.acea.be). According to the information published by this organization the following results were reported on the new passenger car registrations in Europe (EU27 + EFTA) in the years under investigation as presented in million units: 15,$25 ; 15$, $82 ; 16,00 ; 17,47 ; 13,67 ; 13,80 ; 13,61 ; 12,52$. The fall of the new truck (GVW over 3,5 t) registrations in Europe (EU $27+$ EFTA) in thousand units was even more dramatic, which is illustrated by the analogous data: 388,$2 ; 412,5 ; 438,8 ; 428,7 ; 240,4 ; 256,3 ; 324,1$; 305,2 . It may be seen clearly that the falling tendency started in 2008 while in 2012 the market in both cases was lower that the initial level by a dozen or so per cent.

What should also be taken into consideration is that the car industry enterprises are subject to incessant pressure exerted by other processes. Apart from the economic depression, the phenomena that require from the producers a constant progress and adjustment to the growing expectations of the environment regardless of the complicated market situation come to the foreground. The discontinuing of the investments - even in hard times - is in this case equivalent to the slow winding up to the business. Therefore while trying to appraise the situation of the enterprise it is so important to investigate the level of the investments, of the accumulation of capital or the productive potential. Without understanding the mechanisms that determine the development of enterprises of this sector it is impossible to fairly appraise the way that the discussed enterprises chose in order to survive the depression. The sources of potential growth which appear in the production level of the companies of automotive branch lie in the present day level of development of technologies exploited by these companies (Omar, 2011). One of the groups which - from that perspective - is significant is made up by the electronic sub-assemblies (Hollembeak, 2010). The latter - to ever larger extent - relieve the users of performing the control or regulating tasks (Ribbens, 2012). The second group is the group of pro-ecological solutions which affect the fuel consumption or help to meet the standards of exhaust gas cleanness or those that affect the level of noise (Wells, 2010). The next area is made up by the material engineering which is of significance for the resistence of materials, their weight and their responsiveness to various phenomena (Cantor, 2008). What favours the generating of innovations are the growing standards of passenger safety (Pimentel, 2006). Of significance is also the evolution of the process of vehicle projecting (Weber, 2009), both within the scope of complicated instruments applied for this purpose as well as within the scope of effects that are obtained and that determine the ergonomics, comfort and performance (Bhise, 2011). Another area is made up by the solutions that promote the flexibility of production, its automation, improvement of productivity or cost control (Comacchio, 2012). The above review allows to realize the large scope within which the search for potential growth is carried out by the automotive branch companies. This consequently makes visible the scale of challenges that accompany this search (Vogt, 2011). There is, therefore, a large probability that the economic crisis had an impact on the tendency among the respective entities to select some parameters of the way of their development.

\section{RESEARCH METHODS}

There are many companies at the Polish market which may be classified as representatives of the automotive branch. Yet the situation of this sector is determined by the condition of the largest enterprises which are responsible for the dominant part of turnover in this branch of industry. What considerably limits the present analysis is the lack of access to the crucial data. The author assumed that only those firms which made the suitable reports 
public in the entire analyzed period would be taken into account. It was possible to gather the data that characterized the situation of the companies that were responsible for $25 \%$ of the turnover of automotive branch in Poland. Since they belong to the largest companies in their category they therefore determine the situation of their numerous smaller subcontractors. On the basis of the data obtained in GUS (Chief Central Statistical Office in Poland) one could assume that the entire system (including the aforementioned economically dependent suppliers) is responsible for as many as approximately $75 \%$ of the turnover in the discussed branch. Thus, while investigating the situation of the selected group of the largest companies, we arrive at the picture of dynamics characteristic of the key phenomena that dominate in the entire branch. The analysis eventually comprised the following firms: Fiat Auto Poland (further referred to as FAP), Fiat Powertrain Technologies Poland (FPT), Inter Cars (IC), Inter Groclin (IG), Ronal Polska (RP), Sitech (ST), TRW Polska (TRW), Volkswagen Motor Polska (VMP), Volkswagen Poznań (VP), Volvo Polska (VO). The author is aware that the enterprises whose supplies are partly directed towards the „after market” may also be found in the above group. It seems however that in order to depict the full image of the situation of the largest car industry enterprises in Poland in the years 2005-2012 such analysis is nevertheless of cognitive value.

In order to compare - one to another - the condition of the respective companies within one period of time, and also in order to examine the development of their situation within the successive eight years the following variables were employed: turnover $(\mathrm{t})$, net profit $(\mathrm{p})$, assets $(\mathrm{a})$, shareholders' equity (e), investments (i), employment (w). The listed parameters allow to easily estimate the scale of activities of the respective companies (the scale changing under the influence of the observed crisis phenomena) and the probable attitudes of the respective owners towards the prospect of continuing these activities.

\section{RESEARCH RESULTS}

The data for the year 2005 (Tab. 1) show a large distance of the leader (FAP) from the remaining companies as regards the scale of activity since the turnovers of the FAP amounts to one third of the sum of all measured results. However, from the point of view of profitability the hierarchy looks in a totally different way. The enterprise that was characterized by the highest employment (VP) had also the largest profits and made investments within the widest scope although it was lagging behind as regards the turnover.

Tab. 1. Characteristic of the ten leading enterprises of the sector as viewed from the perspective of the beginning of year 2005 (from column ",t" to ,"i" in PLN million)

\begin{tabular}{|l|r|r|r|r|r|r|}
\hline & \multicolumn{1}{c|}{$\mathbf{t}$} & \multicolumn{1}{c|}{$\mathbf{p}$} & \multicolumn{1}{c|}{$\mathbf{a}$} & \multicolumn{1}{c|}{$\mathbf{e}$} & $\mathbf{i}$ & $\mathbf{w}$ \\
\hline FAP & 10077 & 105 & 4322 & 1868 & 79 & 3751 \\
\hline FPT & 3251 & 154 & 2058 & 1035 & 94 & 1255 \\
\hline IC & 613 & 19 & 324 & 91 & 19 & 602 \\
\hline IG & 509 & 43 & 406 & 212 & 47 & 3545 \\
\hline RP & 731 & 23 & 553 & 157 & 40 & 1133 \\
\hline ST & 684 & 112 & 683 & 115 & 131 & 1223 \\
\hline TRW & 1873 & 154 & 739 & 462 & 21 & 2891 \\
\hline VMP & 4368 & 195 & 1131 & 603 & 40 & 1005 \\
\hline VP & 7611 & 309 & 3256 & 935 & 305 & 4800 \\
\hline VO & 1439 & 41 & 475 & 198 & 7 & 1469 \\
\hline sum & 31156 & 1155 & 13947 & 5676 & 783 & 21674 \\
\hline
\end{tabular}

Source: own research on the basis of National Court Register and newspaper publications.

In 2006 the firm that took the lead - according to the criterion of the scale of activity measured by the proportion of turnover - was one which made the most important investments in the earlier period (Tab. 2). What also contributed to this change of the lead was the weakening of the previous leader. The sector as a whole slightly improved its results although this was due to the effort of the active minority in the group of companies that were investigated. What was also characteristic was the limitation of the scope of the investments that were made.

While analysing the data for the successive year, one may observe the appearance of one enterprise that reported a loss (Tab. 3). Likewise, one observes that the turnover and investments grew despite the fall in profit. Therefore we may assume that the branch expects the improvement of the situation in the foreseeable future. The increase in employment also confirms this. In the comparison that was produced the one who occupied the position of the leader two years earlier returned to the top position.

In 2008 all companies in the investigated group of enterprises where found to start with a positive financial result (Tab. 4). There is one result in the analysis of the collected data that draws special attention. This result describes the scale of investments made by the largest firm. This considerably raised the 
Tab. 2. Characteristic of the ten leading enterprises of the sector as viewed from the perspective of the beginning of year 2006 (from column „t to „, PLN million)

\begin{tabular}{|l|r|r|r|r|r|r|}
\hline & \multicolumn{1}{c|}{$\mathbf{t}$} & \multicolumn{1}{c|}{$\mathbf{p}$} & \multicolumn{1}{c|}{$\mathbf{a}$} & $\mathbf{e}$ & $\mathbf{i}$ & $\mathbf{w}$ \\
\hline FAP & 8569 & 296 & 4380 & 1922 & 96 & 3622 \\
\hline FPT & 3704 & 206 & 2291 & 1240 & 73 & 1356 \\
\hline IC & 750 & 1 & 395 & 94 & 0 & 822 \\
\hline IG & 466 & 12 & 404 & 229 & 36 & 3533 \\
\hline RP & 759 & 20 & 529 & 211 & 23 & 1497 \\
\hline ST & 819 & 96 & 634 & 210 & 18 & 1289 \\
\hline TRW & 1983 & 155 & 930 & 617 & 39 & 3099 \\
\hline VMP & 4358 & 127 & 1086 & 535 & 22 & 981 \\
\hline VP & 8706 & 669 & 1415 & 1415 & 105 & 4771 \\
\hline VO & 1365 & 36 & 453 & 193 & 19 & 1924 \\
\hline sum & 31479 & 1618 & 12517 & 6666 & 431 & 22894 \\
\hline
\end{tabular}

Source: own research on the basis of National Court Register and newspaper publications.

Tab. 3. Characteristic of the ten leading enterprises of the sector as viewed from the perspective of the beginning of year 2007 (from column ,t" to , PLN million)

\begin{tabular}{|l|r|r|r|r|r|r|}
\hline & \multicolumn{1}{c|}{$\mathbf{c}$} & $\mathbf{p}$ & \multicolumn{1}{c|}{$\mathbf{a}$} & \multicolumn{1}{c|}{$\mathbf{~}$} & $\mathbf{i}$ & $\mathbf{w}$ \\
\hline FAP & 9225 & 251 & 4064 & 1865 & 182 & 3740 \\
\hline FPT & 4520 & 248 & 2539 & 1488 & 82 & 1389 \\
\hline IC & 1013 & 19 & 445 & 114 & 16 & 1030 \\
\hline IG & 482 & 10 & 445 & 234 & 43 & 3597 \\
\hline RP & 903 & -17 & 538 & 194 & 18 & 1578 \\
\hline ST & 809 & 78 & 551 & 288 & 7 & 1280 \\
\hline TRW & 2181 & 166 & 1158 & 781 & 50 & 3848 \\
\hline VMP & 4301 & 103 & 962 & 511 & 29 & 1087 \\
\hline VP & 8776 & 527 & 2837 & 1703 & 122 & 5584 \\
\hline VO & 1732 & 47 & 678 & 204 & 90 & 2312 \\
\hline sum & 33942 & 1432 & 14217 & 7382 & 639 & 25445 \\
\hline
\end{tabular}

Source: own research on the basis of National Court Register and newspaper publications.

value of the global index. On the other hand the remaining representatives of the sector also increased their investment outlays (in spite of the general fall in profitability).

The data referring to the next of the analysed periods allow to make observations on a series of phenomena (Tab. 5). There were two companies which improved their position with regard to the remainder, two of them reported a fall while six maintained the position they had previously occupied. Two enterprises increased their turnover while eight experienced a decrease in this respect.
The net profit grew in one case (the remainder reported a result that was worse than the one reported a year earlier). Both the assets as well as the employment grew in half of the enterprises while they

Tab. 4. Characteristic of the ten leading enterprises of the sector as viewed from the perspective of the beginning of year 2008 (from column „ $\mathrm{t}$ " to , PLN million)

\begin{tabular}{|l|r|r|r|r|r|r|}
\hline & \multicolumn{1}{c|}{$\mathbf{t}$} & \multicolumn{1}{c|}{$\mathbf{p}$} & \multicolumn{1}{c|}{$\mathbf{a}$} & $\mathbf{e}$ & $\mathbf{i}$ & $\mathbf{w}$ \\
\hline FAP & 11584 & 349 & 5326 & 1964 & 963 & 4669 \\
\hline FPT & 4459 & 175 & 2757 & 1663 & 143 & 1385 \\
\hline IC & 1327 & 58 & 816 & 168 & 65 & 1168 \\
\hline IG & 466 & 1 & 468 & 224 & 25 & 3869 \\
\hline RP & 904 & 11 & 533 & 205 & 47 & 1508 \\
\hline ST & 876 & 67 & 618 & 355 & 10 & 1416 \\
\hline TRW & 2397 & 151 & 1367 & 932 & 71 & 4280 \\
\hline VMP & 4374 & 107 & 940 & 618 & 118 & 1207 \\
\hline VP & 7977 & 369 & 2929 & 2025 & 157 & 6020 \\
\hline VO & 2409 & 39 & 868 & 243 & 48 & 2889 \\
\hline sum & 36773 & 1327 & 16622 & 8397 & 1647 & 28411 \\
\hline
\end{tabular}

Source: own research on the basis of National Court Register and newspaper publications.

Tab. 5. Characteristic of the ten leading enterprises of the sector as viewed from the perspective of the beginning of year 2009 (from column „t" to „i" in PLN million)

\begin{tabular}{|l|r|r|r|r|r|c|}
\hline & \multicolumn{1}{c|}{$\mathbf{c}$} & \multicolumn{1}{c|}{$\mathbf{p}$} & \multicolumn{1}{c|}{$\mathbf{c}$} & $\mathbf{e}$ & $\mathbf{i}$ & $\mathbf{w}$ \\
\hline FAP & 15083 & 312 & 5709 & 2264 & 412 & 5526 \\
\hline FPT & 3857 & 198 & 1832 & 1326 & 79 & 1382 \\
\hline IC & 1738 & 25 & 1228 & 418 & 71 & 2041 \\
\hline IG & 347 & -27 & 360 & 190 & 17 & 2629 \\
\hline RP & 746 & -101 & 609 & 173 & 105 & 1271 \\
\hline ST & 747 & 38 & 524 & 393 & 63 & 1440 \\
\hline TRW & 2273 & 4 & 1503 & 937 & 83 & 4500 \\
\hline VMP & 3796 & 74 & 813 & 590 & 123 & 1171 \\
\hline VP & 7916 & 348 & 3086 & 2160 & 252 & 6133 \\
\hline VO & 1981 & 28 & 861 & 272 & 37 & 2874 \\
\hline sum & 38484 & 899 & 16525 & 8723 & 1242 & 28967 \\
\hline
\end{tabular}

Source: own research on the basis of National Court Register and newspaper publications.

fell in case of the remainder (in reference to the enterprises' own capital and investments we can find the analogous relationship of six to four companies).

The sixth comparison shows the fall in ranking of the two firms, improvement in further two and stabilization of the relative position of the remainder 
(Tab. 6). The turnover grew in four companies while it fell in case of the rest (analogous proportions referred to the changes in the employment level). Six enterprises increased their profits while four reported a worsening in this respect. The enterprises' own assets were found to had been strengthened in seven firms. Also seven firms strengthened their own capital (while in three out of ten the capital and the assets shrank). Three firms increased their outlays on investments (other firms limited this category of expenses).

In the last but one of the examined years the improvement of the relative position of one company. Stabilization was noticed in eight of them and one enterprise reported a fall (Tab. 7). The turnovers and the size of the enterprises' own capital demonstrated a full concordance of changes (the upward movement in eight firms of the same type, the fall being observable in two). The profits improved in seven cases while they deteriorated in three. Assets grew in eight enterprises and fell in two. Increase in investments was noticed in three companies while a reduction was reported in seven of them. Four firms increased their employment while six introduced limitation.

Tab. 6. Characteristic of the ten leading enterprises of the sector as viewed from the perspective of the beginning of year 2010 (from column , $t$ " to „i" in PLN million)

\begin{tabular}{|l|r|r|r|r|r|r|}
\hline & \multicolumn{1}{c|}{$\mathbf{t}$} & \multicolumn{1}{c|}{$\mathbf{p}$} & \multicolumn{1}{c|}{$\mathbf{c}$} & \multicolumn{1}{c|}{$\mathbf{e}$} & $\mathbf{i}$ & $\mathbf{w}$ \\
\hline FAP & 19434 & 820 & 7408 & 2442 & 513 & 6422 \\
\hline FPT & 3216 & 98 & 2214 & 1424 & 67 & 947 \\
\hline IC & 2066 & 68 & 1273 & 499 & 35 & 2105 \\
\hline IG & 171 & 2 & 284 & 182 & 2 & 2099 \\
\hline RP & 702 & 46 & 562 & 218 & 26 & 1219 \\
\hline ST & 858 & 39 & 586 & 438 & 78 & 1417 \\
\hline TRW & 2808 & 210 & 1815 & 1225 & 21 & 4550 \\
\hline VMP & 3317 & 72 & 943 & 560 & 38 & 1151 \\
\hline VP & 7744 & 250 & 3375 & 2358 & 139 & 6194 \\
\hline VO & 1219 & -6 & 747 & 266 & 47 & 2419 \\
\hline sum & 41535 & 1599 & 19207 & 9612 & 966 & 28523 \\
\hline
\end{tabular}

Source: own research on the basis of National Court Register and newspaper publications.

In 2012 the relative position of four companies changed (two of them improved their position while other two lost the places they had previously occupied), (Tab. 8). Almost each company increased its turnover ( nine of them did while one experienced a decrease in this respect). Four companies improved
Tab. 7. Characteristic of the ten leading enterprises of the sector as viewed from the perspective of the beginning of year 2011 (from column "t" to ,"i" in PLN million)

\begin{tabular}{|l|r|r|r|r|r|r|}
\hline & \multicolumn{1}{c|}{$\mathbf{t}$} & \multicolumn{1}{c|}{$\mathbf{p}$} & \multicolumn{1}{c|}{$\mathbf{a}$} & \multicolumn{1}{c|}{$\mathbf{e}$} & $\mathbf{i}$ & $\mathbf{w}$ \\
\hline FAP & 16313 & -82 & 6650 & 2409 & 664 & 6365 \\
\hline FPT & 3731 & 169 & 2404 & 1386 & 53 & 890 \\
\hline IC & 2413 & 64 & 1322 & 559 & 33 & 2258 \\
\hline IG & 141 & 1 & 278 & 184 & 3 & 1563 \\
\hline RP & 911 & 53 & 626 & 271 & 11 & 1218 \\
\hline ST & 876 & 64 & 619 & 483 & 52 & 1547 \\
\hline TRW & 2857 & 249 & 2040 & 1474 & 22 & 4606 \\
\hline VMP & 4312 & 118 & 1032 & 606 & 29 & 1132 \\
\hline VP & 7774 & 290 & 3502 & 2383 & 139 & 6120 \\
\hline VO & 1601 & 33 & 762 & 319 & 27 & 2610 \\
\hline sum & 40929 & 959 & 19235 & 10074 & 1033 & 28309 \\
\hline
\end{tabular}

Source: own research on the basis of National Court Register and newspaper publications.

Tab. 8. Characteristic of the ten leading enterprises of the sector as viewed from the perspective of the beginning of year 2012 (from column "t" to "," in PLN million)

\begin{tabular}{|l|r|r|r|r|r|c|}
\hline & \multicolumn{1}{c|}{$\mathbf{t}$} & \multicolumn{1}{c|}{$\mathbf{p}$} & \multicolumn{1}{c|}{$\mathbf{a}$} & $\mathbf{e}$ & $\mathbf{i}$ & $\mathbf{w}$ \\
\hline FAP & 16471 & 84 & 7035 & 2467 & 854 & 5841 \\
\hline FPT & 4748 & 13 & 3707 & 2341 & 175 & 1130 \\
\hline IC & 2765 & 104 & 1547 & 665 & 45 & 2258 \\
\hline IG & 181 & 1 & 288 & 191 & 3 & 1519 \\
\hline RP & 1082 & 74 & 680 & 280 & 94 & 1242 \\
\hline ST & 1191 & 105 & 728 & 524 & 39 & 1444 \\
\hline TRW & 2776 & 121 & 2176 & 1594 & 37 & 4606 \\
\hline VMP & 4466 & 107 & 1147 & 595 & 22 & 1161 \\
\hline VP & 9822 & 281 & 3626 & 2036 & 202 & 6152 \\
\hline VO & 2180 & 19 & 812 & 292 & 52 & 2652 \\
\hline sum & 45682 & 909 & 21746 & 10985 & 1523 & 28005 \\
\hline
\end{tabular}

Source: own research on the basis of National Court Register and newspaper publications.

their profits while five reported worsening (one company maintaining the situation of the previous year). Investments increased in seven cases, in two they fell and in one case their size remained intact. The enterprises' own capital was strengthened in seven firms, it was reduced in three of them but each firm collected more assets. Five companies increased the employment while other three reduced it and two other kept it unchanged. 


\section{DISCUSSION OF THE RESULTS}

While analysing all results obtained by the enterprises under research (Tab. 9) one may notice a general growth of their turnovers in 2005-2012. Simultaneously, in the last three years tunder investigation a tendency to reduce the employment was observed. Among various significant phenomena there is also visible an Interdependence is also visible among various significant phenomena. It is detectable in the concordance of the trends of changes of the sum of assets of all enterprises and the scope of investments jointly made by these enterprises.

As regards the turnover, between 2005 and 2012 the companies under research increased it by about $50 \%$. Taking into account the inflation index the turnover grew by $31 \%$, which proves that the turnovers actually grews. With the exception of 2011, one deals with the positive dynamics of changes. That indicates the occurrence of soft, stabile rising trend. While considering the dynamics of the turnover of each of the ten enterprises one can make some interesting observations. The biggest success can be attributed to IC. The worst result was found in case of IG. The results of the majority of the entities showed high level of variability. The most stable record was observed for VMP.

In case of the data that describe the changes of the net profit level in 2005-2012 one deals with remarkable turbulent situation. After the maximum reached in 2006 there occurred a collapse the minimum of which was detectable three years later (this corresponding to the period when the problems of the sector reached

Tab. 9. Comparison of aggregated characteristics of the group of enterprises representing the sector in 2005-2012 (from column „t" to „i" in PLN million)

\begin{tabular}{|c|c|r|c|r|r|c|}
\hline & $\mathbf{t}$ & $\mathbf{p}$ & $\mathbf{a}$ & $\mathbf{e}$ & $\mathbf{i}$ & $\mathbf{w}$ \\
\hline 2005 & 31156 & 1155 & 13947 & 5676 & 783 & 21674 \\
\hline 2006 & 31479 & 1618 & 12517 & 6666 & 431 & 22894 \\
\hline 2007 & 33942 & 1432 & 14217 & 7382 & 639 & 25445 \\
\hline 2008 & 36773 & 1327 & 16622 & 8397 & 1647 & 28411 \\
\hline 2009 & 38484 & 899 & 16525 & 8723 & 1242 & 28967 \\
\hline 2010 & 41535 & 1599 & 19207 & 9612 & 966 & 28523 \\
\hline 2011 & 40929 & 959 & 19235 & 10074 & 1033 & 28309 \\
\hline 2012 & 45682 & 909 & 21746 & 10985 & 1523 & 28005 \\
\hline
\end{tabular}

Source: own research on the basis of National Court Register and newspaper publications. their climax). Despite a one-time correction in the successive year the value of the profit obtained in the last period stabilized at the level that was far from the optimal one. Taking into account the inflation index one can say that these results demonstrate a weakening position of the group of enterprises under investigation. While considering the dynamics of the net profit of each of the ten enterprises one can notice that an impressive progress was made by IC. Four enterprises (FAP, IG, RP, VO) showed negative results but the most negative tendency was observed in case of FPT and IG.

The data that indicates the accumulation of the assets in 2005-2012 show the rising tendency. While comparing the first year and the last year one may say that (despite individual results that are worse in 2006, $2009,2011)$ its growth resembles that which was reported in case of the turnover. While considering the dynamics of the assets of each of the ten investigated enterprises one may find that the most impressive increase of assets was observed in case of IC. TRW was found to be the most successful in the continuing, systematic, stable growth of the amount of assets year by year. While comparing the first and the last year, it is possible to find that only IG showed negative result.

The analysis of the data that illustrates the change of the size of the own capital of all examined enterprises points - in absolute values - to the almost one hundred per cent growth. Even if one takes the inflation index into account, this is the evidence of the scope of capital accumulation that took place in the examined period. What is worth emphasizing is the fact that each year was - in this respect - always better than the previous one. Likewise, it is noteworthy that the rising tendency points to the exceptional stability and consistency in the behaviour of the companies under investigation. While considering the dynamics of the equity of each of the ten enterprises one may also make some interesting observations. The biggest increase was observed in case of ST and TRW. Remarkable decrease can be found only in case of IG but minimal increase was also observed in case of VMP.

In case of the analysed data that illustrates the investment level, there emerges a picture which indicates the highly turbulent nature of a behaviour of the enterprises in this respect. The observed changes point to the wave-like course illustrating how the investment efforts were made: after the period of violent growth and intense outlays there followed a equally strong hold up (minima occurring in 2006 
and on 2010). The observed period is too short to allow the assessment of regularity of this phenomenon. Yet one may take into consideration a question whether, in this case, we deal with the four-year cycle. While considering the dynamics of the investments made by each of the ten discussed enterprises one may notice that in case of almost all of them the investment level was very high in the year 2008. The gradual reduction of investment (systematic tendency to reduce this rate) was demonstrated by IG. Generally the dynamics of the individual rate of investment was usually fairly variable from one year to another.

The data that illustrates the changes in the employment level index (which came into being after the data characterizing the group of all investigated enterprises have been summed up) resembles the description of the phases of market development. After the period of an opening growth one observe sthe acceleration, stabilization and diversion that initiates the a slow decline. This may indicate the improvement in the employment in the last years, which should bring about the effects assuming the shape of increased effectiveness in operation. While considering the dynamics of the rate of employment in each of the ten investigated enterprises one can make some additional observations. Around the year 2008 the rate of employment was at the highest level in case of the majority of investigated entities and then usually stabilized around this level for a longer time (f.e. IC, ST, TRW, VMP, VP) but in some cases (RP and VO) the rapid increase was followed by similarly rapid decrease at the end of the period taken into consideration. Only in case of IG there was a permanent and deep fall of employment.

In case of the investigated group of companies treated as a whole, the most difficult years of the crisis (that is the years 2007 and 2008) proved to be the point that commenced the developmental phase (Tab. 9). It was exactly from that moment that an systematic growth of turnovers was observable while the level of investments and the employment level oscillated round the values considerably higher than those characteristic of the initial period of observation. On the other hand, what was noticeable was the fall of average profitability of the companies of the branch. This fall of profitability was accompanied by the simultaneous growth of the assets and shareholders' equity. Obviously, this picture, when split into the individual cases of the respective companies, may remarkably depart from the average values. In this context the extreme cases are presented by the entities referred to as IC and IG (Tab. 10). What is characteristic, however, is that within the investigated period one generally deals with the noticeable conformity of the scope and the direction of changes of the respective parameters that describe the individual ups and downs of a given firm. The analysis of the coefficients of correlation

Tab. 10. Percentage change of the level of the respective parameters as found between 2005 and 2012

\begin{tabular}{|l|r|r|r|r|r|r|}
\hline & \multicolumn{1}{c|}{$\mathbf{t}$} & \multicolumn{1}{c|}{$\mathbf{p}$} & \multicolumn{1}{c|}{$\mathbf{a}$} & \multicolumn{1}{c|}{$\mathbf{~}$} & \multicolumn{1}{c|}{$\mathbf{i}$} & \multicolumn{1}{c|}{$\mathbf{w}$} \\
\hline FAP & 63 & -20 & 63 & 32 & 981 & 56 \\
\hline FPT & 46 & -92 & 80 & 126 & 86 & -10 \\
\hline IC & 351 & 447 & 377 & 631 & 137 & 275 \\
\hline IG & -64 & -98 & -29 & -10 & -94 & -57 \\
\hline RP & 48 & 222 & 23 & 78 & 135 & 10 \\
\hline ST & 74 & -6 & 7 & 356 & -70 & 18 \\
\hline TRW & 48 & -21 & 194 & 245 & 76 & 59 \\
\hline VMP & 2 & -45 & 1 & -1 & -45 & 16 \\
\hline VP & 29 & -9 & 11 & 118 & -34 & 28 \\
\hline VO & 51 & -54 & 71 & 47 & 643 & 81 \\
\hline
\end{tabular}

Source: own research.

as based on the above presented data allows to ascertain that all parameters that were taken into consideration have strong mutual reference. Each time when the value of correlation coefficient is being obtained it is close to 1 (but in one case - that which involves the investment - one deals with the reference shifted by two years). It is therefore possible to discern certain consistency in the behaviour of the entire group of the investigated companies in each of the examined areas. During the global crisis affecting the discussed branch it was the dominating majority of entities that managed to enlarge the scale of conducted activities. This proves that the discussed companies were successful in selecting an effective strategy of progressing by the development in a safe market niche.

\section{CONCLUSIONS}

While concluding the conducted analysis one may find that in the context of the market situation in Europe in the automotive branch the Polish enterprises were found to be in a fairly good condition by 2012 (after the climax of the economic crisis). Obviously, the profitability (particularly in comparison with the amount of turnover) was not so impressive but still each enterprise was profitable. 
During these eight years it was the priority for the enterprises to build their modern productive potential based on investments and preservation of the skilled working power. These enterprises were able to attract capital, investors and the attention of the staff of headquarters of the biggest automotive corporations. Of course it was easier to reach these ends by these enterprises which were also parts of international automotive corporations. Their success was also connected with the process of competing with other plants located in other European countries. But certainly, also purely Polish enterprises were able to extend their activities (for example IC) in spite of the case of IG which diminished the proportion of the latter. Generally, one may find that in case of each enterprise the rate of efficiency was on a very high level, which proved that the Polish automotive enterprises were - during all these years - very competitive and that their strategy to invest in production technologies, to control costs and to preserve skilled working power was the right way to strengthen their market position. The author also hopes to open further discussion which might provide a deeper insight into the situation of similar enterprises in other European countries in the same period of time.

\section{LITERATURE}

Domansky, L. R. (Ed.). (2006). Automobile Industry. Current Issues. New York, USA: Nova Science Publishers.

Bhise, V. D. (2011). Ergonomics in the Automotive Design Process. Boca Raton, London, New York: CRC Press, Taylor \& Francis Group.

Brinkmann, L. (2011). Global competitiveness of the car industry. Norderstedt, Germany: GRIN Verlag.

Cantor, B., Grant, P., \& Johnston, C. (2008). Automotive Engineering: Lightweight, Functional, and Novel Materials. Boca Raton, London, New York: CRC Press, Taylor \& Francis Group.

Comacchio, A., Volpato, G., \& Camuffo, A. (2012). Automation in Automotive Industries: Recent Developments. London, Great Britain: Springer London, Limited.

European Automobile Manufacturers Association (2015, September 02). Retrieved from http://www.acea.be

Freyssenet, M., Shimizu, K., \& Volpato, G. (Eds.). (2003). Globalization Or Regionalization of the European Car Industry? London, New York: Palgrave Macmillan.

Hollembeak, B. (2010). Advanced Automotive Electronic Systems. New York, USA: Delmar, Cengage Learning.

Keeley, B., \& Love, P. (2010). OECD Insights From Crisis to Recovery The Causes, Course and Consequences of the
Great Recession: The Causes, Course and Consequences of the Great Recession. OECD Publishing.

Omar, M. A. (2011). The Automotive Body Manufacturing Systems and Processes. Chichester, Great Britain: John Wiley \& Sons.

Peters, N. (2009). The impact of the global downturn on the car manufacturing industry. Norderstedt, Germany: GRIN Verlag.

Pimentel, J. R. (2006). Safety-critical automotive systems. International Society of Automotive Engineers.

Ribbens, W. (2012). Understanding Automotive Electronics: An Engineering Perspective. Waltham, USA: Butterworth-Heinemann.

Vogt, J. (2011). Value Creation Within the Construction Industry: A Study of Strategic Takeovers. Frankfurt, Germany: Peter Lang GmbH.

Weber, J. (2009). Automotive Development Processes: Processes for Successful Customer Oriented Vehicle Development. Springer Science \& Business Media.

Wells, P. E. (2010). The Automotive Industry in an Era of Eco-austerity: Creating an Industry as If the Planet Mattered. Cheltenham, Great Britain; Northampton, USA: Edward Elgar Publishing. 